\title{
Pseudodiastrophic dysplasia
}

INSERM

\section{Source}

INSERM. (1999). Orphanet: an online rare disease and orphan drug data base.

Pseudodiastrophic dysplasia. ORPHA:85174

Pseudodiastrophic dysplasia is characterized by rhizomelic shortening of the limbs and severe clubfoot deformity, in association with elbow and proximal interphalangeal joint dislocations, platyspondyly, and scoliosis. It has been described in about 10 patients. An autosomal recessive inheritance has been suggested. Pseudodiastrophic dysplasia differs from diastrophic dysplasia (see this term) on the basis of clinical, radiographic, and histopathologic findings. Clubfoot can be treated by surgical therapy, and neonatal contractures and scoliosis can be relieved by physical therapy. Several of the reported patients died in the neonatal period or during infancy. 